\title{
Glutamine Transport in Rat Kidney Mitochondria in Metabolic Acidosis
}

\author{
William Adam and Davm P. Simpson \\ Departments of Medicine and Physiology, University of Washington, Seattle, \\ Washington 98195, and the U.S. P. H. S. Hospital, Seattle, Washington 98114
}

A в S T R A C T In order to study factors regulating renal ammoniagenesis, the transport and metabolism of $\mathrm{L}$ glutamine were studied in mitochondria from kidneys of control and acidotic rats. On incubation in $1 \mathrm{mM}$ $\left[{ }^{14} \mathrm{C}\right]$ glutamine, there was production and accumulation of $\left[{ }^{14} \mathrm{C}\right]$ glutamate within the matrix space. However no $\left[{ }^{14} \mathrm{C}\right]$ glutamine was detected in the matrix space, even with $10 \mathrm{mM}\left[{ }^{14} \mathrm{C}\right]$ glutamine as substrate or with inhibition of glutamine deamidation (low temperature, $p$-chloromercuribenzoate, mersalyl). These results suggest that glutamine crosses the inner membrane by a carrier-mediated step and that this step is rate-limiting in glutamine deamidation.

In chronic acidosis there is a fourfold increase in the uptake of radioactivity from $\left[{ }^{14} \mathrm{C}\right]$ glutamine, but not from $\alpha$-ketoglutarate, glutamate, or acetate. In 3 -h acidosis, before any increase in extracted glutaminase levels, there is a significant and reproducible increase $(39 \pm 3.8 \%, n=25)$ in matrix uptake of radioactivity from $\left[{ }^{14} \mathrm{C}\right]$ glutamine and also an increased ammonia production $(17 \pm 3.7 \%, n=12)$.

Administration of furosemide produces a similar degree of potassium depletion and a greater degree of sodium depletion over $3 \mathrm{~h}$ when compared to a 3 - $\mathrm{h}$ acidosis. However, it produces no change in mitochondrial uptake of radioactivity.

These results show that the adaptation of renal glutamine metabolism observed in acidosis is due to the acidosis and is demonstrable in isolated rat kidney mitochondria. The site of adaptation is in the carrier system, which transports glutamine across the inner membrane. The increased transport in acidosis delivers more glutamine to glutaminase, which results in the increased renal ammonia production.

Dr. Adam is the recipient of a Public Health Service International Fellowship (FO5 TW 1816); his present address is Department of Medicine, Austin Hospital, Heidelberg, Victoria, 3084 Australia.

Received for publication 1 November 1973 and in revised form 21 January 1974.

\section{INTRODUCTION}

In metabolic acidosis in some mammals, including man, homeostasis is maintained by a several-fold increase in the ability of the kidney to excrete hydrogen ions as the ammonium complex. The increased ammonium excretion is derived mainly from increased renal production from glutamine by the following reaction:

L-glutamine amidohydrolase

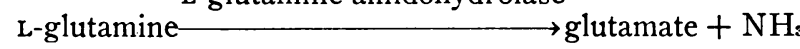
(The evidence for these statements has been extensively reviewed. See 1, 2.) Glutaminase (L-glutamine amidohydrolase, EC 3.5.1.2) is an intramitochondrial enzyme, found in the inner membrane or matrix fraction $(3,4)$ and thus this reaction is also intramitochondrial. Glutaminase consists of two isoenzymes, one phosphatedependent $(\mathrm{PDG})^{1}$ and the other phosphate-independent (PIG) (5). PDG is probably more important than PIG in this reaction, at least in the rat, since its level in kidney is about 10 times greater than PIG (5) and it is the only one of the two in which increased levels have been demonstrated in association with the increased renal ammonia production of acidosis (6). There is also an extramitochondrial glutaminase system (glutamine-keto acid transaminase, $\omega$ amidase), but this is thought not to play an important role in this situation $(7,8)$.

Because of the intramitochondrial location of glutaminase and of the enzymes responsible for metabolism of glutamate, knowledge of the properties and functions of mitochondria from renal cortex, as they affect glutamine, is essential in attempting to understand regulation of renal ammoniagenesis. Mitochondria consist of an outer space surrounded by an outer membrane and an inner or matrix space surrounded by an inner membrane. The outer membrane is freely permeable to small ions

${ }^{1}$ Abbreviations used in this paper: DON, 6-diazo-5-oxoL norleucine; HEPES, $N$-2-hydroxyethylpiperazine- $N^{\prime}-2$ ethane sulfonic acid; PCMB, $p$-chloromercuribenzoate; PDG, phosphate-dependent glutaminase; PIG, phosphateindependent glutaminase. 
and molecules. In contrast, the inner membrane is passively impermeable to most ions and to uncharged molecules such as sucrose and mannitol. The enzymes of the citric acid cycle and related processes are either located in the matrix space or attached to the inner membrane (9). For substrates in the cytoplasm to reach these enzymes, they must penetrate the inner mitochondrial membrane, and a number of group-specific active transport systems exist in this membrane which convey substrates such as $\alpha$-ketoglutarate, glutamate, and citrate from the outer space across the inner membrane into the matrix space. (For review article, see ref. 10).

The intramitochondrial location of PDG is not precisely known, but it is either attached to the inner membrane or situated in the matrix space $(3,4)$. Therefore it is possible that glutamine, like many other substrates, is transported across the inner membrane by a specific carrier. If so, the rate of transport by the carrier might regulate the rate of delivery of glutamine to glutaminase and hence control the rate of ammoniagenesis. The increase in ammonia production in metabolic acidosis might result from an adaptation of this carrier system resulting in more rapid delivery of glutamine to glutaminase. This paper describes experiments designed to evaluate these possibilities. The results indicate that a carrier for glutamine does exist in the inner membrane and that an adaptive increase in the capacity of this carrier is probably the factor primarily responsible for the increased ammonia production in metabolic acidosis.

\section{METHODS}

\section{General}

Sprague-Dawley rats, $200-300 \mathrm{~g}$, maintained on Purina Laboratory Chow (Ralston Purina Co., St. Louis, Mo.) were used (control plasma bicarbonate concentration $28 \pm 0.3$ meq/liter, $n=49$ ). Acidosis was induced by ingestion of $0.28 \mathrm{M}$ ammonium chloride as sole drinking fluid for 5-7 days in the chronic studies (plasma bicarbonate concentration $12 \pm 1.1 \mathrm{meq} / \mathrm{liter}, n=22$ ) and $2.0 \mathrm{ml} / 100 \mathrm{~g}$ of 1.0 $\mathrm{M}$ by intragastric tube for the 3 -h studies (plasma bicarbonate concentration $14 \pm 0.6 \mathrm{meq} / \mathrm{liter}, n=49)$. Shortterm volume and potassium depletion was produced by intraperitoneal furosemide $(0.5 \mathrm{mg})$. Urinary sodium and potassium excretion was measured in conscious rats as described previously (11) $3 \mathrm{~h}$ after water, $\mathrm{NH}_{4} \mathrm{Cl}$, or furosemide.

The rats were killed by decapitation and blood collected for plasma bicarbonate determination. The kidneys were removed immediately and placed in an ice-cold solution $(0.14 \mathrm{M} \mathrm{NaCl}, 0.01 \mathrm{M} \mathrm{KCl})$ for preparation of a mitochondrial fraction by a method derived from that of Chappell and Hansford (12). The kidneys were decapsulated, papillectomized, diced, and then homogenized in 0.3 $\mathrm{M}$ sucrose, $5 \mathrm{mM} N$-2-hydroxyethylpiperazine- $N^{\prime}$-2-ethane sulfonic acid (HEPES), $1 \mathrm{mM}$ EDTA, $\mathrm{pH} 7.4$, by six passes of a Teflon pestle at 70-90 rpm in a glass tube with a $0.3-\mathrm{mm}$ clearance. After an initial centrifugation at 1,000 $g$ for $5 \mathrm{~min}$, the supernate was centrifuged for $12 \mathrm{~min}$ at

\section{W. Adam and D. P. Simpson}

$7,000 \mathrm{~g}$; centrifugation was repeated twice after resuspension of the pellet by the cold finger technique in $0.3 \mathrm{M}$ sucrose, $5 \mathrm{mM}$ HEPES, $\mathrm{pH}$ 7.4. The final suspension was in $0.3 \mathrm{M}$ sucrose at a protein concentration of $20-40 \mathrm{mg} /$ $\mathrm{ml}$. The protein concentrations were adjusted so that there was less than $10 \%$ difference between samples compared in an individual experiment.

\section{Experimental}

For measurement of glutamine uptake, the medium contained (unless otherwise stated) $1 \mathrm{mM} \mathrm{L}-\left[\mathrm{U}-{ }^{14} \mathrm{C}\right]$ glutamine, $130 \mathrm{mM} \mathrm{KCl}, 20 \mathrm{mM}$ HEPES, $\mathrm{pH} \mathrm{7.4,} 0.5 \mathrm{mM} \mathrm{MgSO}_{4}, 1$ $\mathrm{mM} \mathrm{Na}$ arsenite, and $1 \mu \mathrm{g} / \mathrm{ml}$ rotenone (the latter two constituents inhibit metabolism after glutamate formation). $\left[{ }^{2} \mathrm{H}\right]$ mannitol was added to measure concurrently the outer space of the mitochondria. Parallel experiments were run with tritiated water and $\left[{ }^{14} \mathrm{C}\right]$ sucrose to determine the relationship of outer space to total mitochondrial water and thus allow derivation of the inner water space (13). The incubation and separation of mitochondria from the medium were performed by three different methods;

Silicone layer. The medium $(100 \mu 1)$ was layered in microcentrifuge tubes containing a layer of $50 \mu 1$ silicone oil $^{2}$ above $50 \mu 1$ of either $1 \mathrm{M}$ perchloric acid (when the pellet was counted directly) or $0.1 \mathrm{M}$ perchloric acid in $0.6 \mathrm{M}$ sucrose (when $\left[{ }^{14} \mathrm{C}\right]$ glutamine was separated from $\left[{ }^{14} \mathrm{C}\right]$ glutamate). The cap of the tube had been pierced by an 18-gauge needle producing a hole $1 \mathrm{~mm}$ or more in diameter and the mitochondria $(20 \mu 1)$ were placed in this cap. Incubation was started by an initial centrifugation at slow speed for approximately $2 \mathrm{~s}$ in a Beckman 152 Microfuge (Beckman Instruments, Inc., Spinco Div., Palo Alto, Calif.). This slow centrifugation was sufficient to transfer the mitochondria from the cap into the medium without causing them to penetrate the silicone layer. The incubation was terminated at set times by further centrifugation at full speed leading to rapid separation of the mitochondria from the medium and quenching in the acid layer. This method is an adaptation of one previously described (14) and unless otherwise stated was the method used in the experiments in this paper.

Pellet. The mitochondria $(20 \mu 1)$ were added directly to $100 \mu \mathrm{l}$ of medium in a microcentrifuge tube mixed with a vortex mixer and separated by centrifugation for $45 \mathrm{~s}$ at top speed of the microcentrifuge. The pellet was then quenched in $0.1 \mathrm{M}$ perchloric acid, with a total delay from commencement of the first centrifugation of less than $2 \mathrm{~min}$. Millipore filtration. The mitochondria $(100 \mu \mathrm{l})$ were incubated in a glass test tube and then separated, and the reaction was terminated by Millipore filtration (Millipore Corp., Bedford, Mass.). $60 \mathrm{lb} / \mathrm{in}^{2}$ of nitrogen were applied to the mixture on a $0.45-\mu \mathrm{m}$ pore size Millipore filter and the paper was washed with $8 \mathrm{ml}$ of ice-cold $0.3 \mathrm{M}$ sucrose, dried, and placed in $0.1 \mathrm{M}$ perchloric acid.

Of these three methods, the silicone layer technique provided reliable results for the measurement of the volumes of mitochondrial fluid spaces and for the determination of the volume of distribution of glutamine in these spaces. For the latter, it was necessary to study glutamine distribution under conditions in which the metabolism of glutamate was slowed either by low temperature or by inhibitors. Otherwise a significant amount of glutamine was metabolized during passage through the silicone layer, which required about $4 \mathrm{~s}$, resulting in volumes of distribution

${ }^{2}$ Versilube F-50, lot 1035, General Electric Co., Schenectady, N. Y. 
less than the size of the outer space (see Results). The pellet technique was useful for determining volumes of mitochondrial spaces for comparison with those obtained with the silicone layer method. However, it could not be used for estimating the volume of distribution of glutamine, since the time required for preparation of the mitochondrial extract after separation of pellet and medium was long enough so that even at $4^{\circ} \mathrm{C}$, almost all of the glutamine in the outer space was converted to glutamate. The Millipore method separated mitochondria from medium very quickly and provided confirmatory data on the distribution of glutamine. However, with this technique, some of the mitochondrial fluid was lost when the mitochondria were washed, so that reliable outer space measurements were not obtainable.

Perchloric acid extracts of mitochondria were either counted directly for total ${ }^{14} \mathrm{C}$ or promptly neutralized with $0.1 \mathrm{M} \mathrm{KOH}$ and placed on a $15 \times 0.4-\mathrm{cm}$ column of Dowex $1 \times 8, \quad 50-100$ mesh, formate form (15). $\left[{ }^{14} \mathrm{C}\right]$ glutamine was recovered in a $5-\mathrm{ml}$ water wash and after another $5-\mathrm{ml}$ water wash, which was discarded, the $\left[{ }^{14} \mathrm{C}\right]$ glutamate was eluted from the column with $10 \mathrm{ml} 0.1 \mathrm{~N}$ formic acid. Recovery of labeled compounds in these fractions in control experiments was $97 \% \pm 1.6 \quad(n=10)$ for $\left[{ }^{14} \mathrm{C}\right]$ glutamine and over $90 \%$ for $\left[{ }^{14} \mathrm{C}\right]$ glutamate, with less than $5 \%$ cross-contamination of the water by the acid fraction and less than $1 \%$ cross-contamination of acid by the water fraction. A linear rate of ammonia production by intact mitochondria was obtained by incubating them for 3-10 min at $37^{\circ} \mathrm{C}$ in a medium similar to that used for the $\left[{ }^{14} \mathrm{C}\right]$ glutamine uptake experiments, except that the mitochondrial protein concentration was only $0.4-0.8 \mathrm{mg} / \mathrm{ml}$ and $2 \mathrm{mg} / \mathrm{ml}$ of fatty acid-poor albumin and $1 \mathrm{mM}$ oxaloacetate $^{3}$ were present in the medium. The reaction was terminated by the addition of $\mathrm{HClO}_{4}$ and then neutralized immediately with $\mathrm{KOH}$. PDG levels were determined by measuring ammonia production under optimal conditions with borate extracts of lyophilised mitochondria (8).

Oxygen consumption was measured in mitochondria with a Clark-type oxygen electrode (Yellow Springs Instruments Co., Yellow Springs, Ohio) with a medium containing $10 \mathrm{mM}$ malate, $10 \mathrm{mM}$ pyruvate, $135 \mathrm{mM}$ sucrose, $58 \mathrm{mM} \mathrm{KCl}, 1.3 \mathrm{mM} \mathrm{KH}_{2} \mathrm{PO}_{4}, 8.7 \mathrm{mM} \mathrm{K} \mathrm{HPO}_{4}, 5 \mathrm{mM}$ $\mathrm{MgSO}_{4}$, and $5 \mathrm{mg}$ bovine serum albumin, $\mathrm{pH}$ 7.4.

\section{Chemical measurements}

Ammonia was measured by the alkaline phenate method after separation from the remaining glutamine by column chromatography (16). Plasma bicarbonate was measured by a titrametric method (17), sodium and potassium by internal standard flame photometry, and protein was determined by the biuret method (18) on the original mitochondrial fractions and by the method of Lowry, Rosebrough, Farr, and Randall (19) on diluted mitochondria and glutaminase extracts. Radioactivity was measured in a Packard Tricarb liquid scintillation counter (Packard Instrument Co., Inc., Downer Grove, Ill.). The samples were made up to $1 \mathrm{ml}$ with water (polypropylene vials) or $1 \mathrm{mM}$

${ }^{3}$ The addition of oxaloacetate stimulates $\mathrm{NH}_{3}$ production 4-10-fold in this situation by removal of matrix space glutamate through glutamate oxaloacetate transaminase. Under these conditions the presence or absence of rotenone in medium, or oxygenation made no difference in the results obtained (W. R. Adam and D, P. Simpson. Unpublished observation). glutamine in water (glass vials) and added to $14 \mathrm{ml}$ of scintillation fluid (toluene $1,000 \mathrm{ml}$, Triton X-100 $333 \mathrm{ml}$, 2,5-diphenyloxazole $6 \mathrm{~g}$, bis-2-(4-methyl-5-phenyloxazoyl) benzene $0.5 \mathrm{~g}$ ). Efficiency of counting was assessed by automatic external standardization and did not vary by more than $10 \%$.

\section{Calculations}

The volume of the mitochondrial water was calculated for each mitochondrial incubation preparation from the known specific activity in disintegrations per minute per milliliter of $\left[{ }^{3} \mathrm{H}\right]$ water in the medium and the ${ }^{8} \mathrm{H}$ radioactivity found in each mitochondrial extract. The outer space was calculated from the ratio of $\left[{ }^{14} \mathrm{C}\right]$ sucrose: $\left[{ }^{3} \mathrm{H}\right]$ water in the extract divided by that ratio in the medium, and the matrix space calculated by subtracting the outer space from the total water space. The outer space was also calculated in the presence of $\left[{ }^{14} \mathrm{C}\right]$ glutamine by the distribution of $\left[{ }^{3} \mathrm{H}\right]$ mannitol and the matrix space in these samples calculated from the ratio of matrix to outer space obtained from those samples containing $\left[{ }^{3} \mathrm{H}\right]$ water and $\left[{ }^{14} \mathrm{C}\right]$ sucrose. The term "outer space" as used here includes the volume of medium adherent to the outside of the mitochondria.

From the known specific activity of glutamine in the medium and from the measured outer space in each sample, the number of ${ }^{14} \mathrm{C}$ disintegrations per minute in the outer space was calculated. (We assumed that the outer space was filled with medium by simple diffusion.) This quantity was subtracted from the total ${ }^{14} \mathrm{C}$ radioactivity measured in the mitochondrial extract to give the total ${ }^{14} \mathrm{C}$ radioactivity present in the matrix space. The ratio of total ${ }^{14} \mathrm{C}$ radioactivity per microliter of matrix space to the ${ }^{14} \mathrm{C}$ concentration in the medium is defined as the matrix ${ }^{14} \mathrm{C}$ uptake.

\section{Materials}

Radiochemicals were obtained from New England $\mathrm{Nu}$ clear, Boston, Mass. The $\left[{ }^{14} \mathrm{C}\right]$ glutamine was purified on the morning of use by column chromatography, as described for its determination. Unlabeled glutamine and other substrates were Calbiochem A grade (Calbiochem, San Diego, Calif.). Ion exchange resins were obtained from Bio-Rad Laboratories, Richmond, Calif. 6-diazo-5-oxo-Lnorleucine (DON) and azaserine were gifts from the Cancer Chemotherapy National Service Center, National Cancer Institute, Bethesda, $\mathrm{Md}$.

\section{RESULTS}

Mitochondrial spaces and oxygen consumption. By the silicone layer method, the matrix space, that is the sucrose-impermeable space, averaged $25 \%$ of the total water space and was approximately $0.8 \mu \mathrm{l} / \mathrm{mg}$ of mitochondrial protein. The spaces were no different in the control or acidotic rats (Table I). Matrix space measurements with the pellet method gave results similar to those obtained with the silicone layer method (Table I). The differences in outer space volumes as determined by the silicone layer and pellet methods were the result of the presence of a larger amount of adherent medium in mitochondria separated by the silicone layer technique. Oxygen consumption and ADP:O ratios in control and acidotic animals are shown in Table II. No significant differences between the two 
TABLE I

Mitochondrial Total Water, Matrix, and Outer Space Measurements as Obtained by Silicone Layer and Pellet Techniques

\begin{tabular}{lccccc}
\hline \multicolumn{1}{c}{ Technique } & $n$ & $\begin{array}{c}\text { Total } \mathrm{H}_{2} \mathrm{O} \\
\text { space }\end{array}$ & Outer space & \multicolumn{2}{c}{ Matrix space } \\
\hline & & $\mu l / m g$ protein & $\mu l / m g$ protein & $\%$ of $\mathrm{H}_{2} \mathrm{O}$ space & $\mu l / m g$ protein \\
Silicone layer & & & & & \\
$\quad$ Control & 25 & $3.1 \pm 0.15$ & $2.3 \pm 0.12$ & $26.0 \pm 0.93$ & $0.80 \pm 0.04$ \\
3-h acidosis & 12 & $3.4 \pm 0.13$ & $2.6 \pm 0.10$ & $23.6 \pm 1.03$ & $0.80 \pm 0.05$ \\
Chronic acidosis & 18 & $2.8 \pm 0.14$ & $2.0 \pm 0.10$ & $28.6 \pm 1.12$ & $0.78 \pm 0.05$ \\
Pellet & & & & & \\
$\quad$ Control & 5 & $1.61 \pm 0.08$ & $0.63 \pm 0.05$ & $61 \pm 2.9$ & $0.99 \pm 0.08$ \\
Chronic acidosis & 5 & $1.56 \pm 0.08$ & $0.59 \pm 0.08$ & $63 \pm 3.6$ & $0.97 \pm 0.05$ \\
\hline
\end{tabular}

groups were present in these measurements. In addition, neither control nor acidotic mitochondria metabolized externally added NADH.

These results show that the mitochondria used in these experiments had characteristics usually found in mitochondrial preparations of good quality (12). They also show that the mitochondria from control and acidotic animals were comparable in their ability to perform oxidative phosphorylation and in the relative sizes of the matrix and total water spaces.

Distribution of $\left[{ }^{14} \mathrm{C}\right]$ glutamine and formation of $\left[{ }^{11} \mathrm{C}\right]$ glutamate in kidney mitochondria. In preliminary experiments, we found that mitochondria incubated with $\left[{ }^{14} \mathrm{C}\right]$ glutamine took up and concentrated radioactivity in the matrix space. On analysis of the constituents of this uptake, we found that nearly all of the ${ }^{14} \mathrm{C}$ in the matrix space could be accounted for as $\left[{ }^{14} \mathrm{C}\right]$ glutamate, and that we could not demonstrate any $\left[{ }^{14} \mathrm{C}\right]$ glutamine within the matrix space. Experiments were then carried out under a variety of conditions to document and extend these findings.

Mitochondria from control rats were incubated for $60 \mathrm{~s}$ in $1 \mathrm{mM}$ glutamine medium either at room temperature $\left(21-24^{\circ} \mathrm{C}\right)$ or at $4^{\circ} \mathrm{C}$ and in $10 \mathrm{mM}$ glutamine at room temperature. In none of these situations did the amount of $\left[{ }^{14} \mathrm{C}\right]$ glutamine present in the mitochondrial pellet exceed the quantity calculated to be present in the mitochondrial outer space by simple diffusion

TABLE II

Oxygen Electrode Data on Mitochondria from Control and Chronic Acidotic Rat Kidneys with Malate and Pyruvate as Substrates

\begin{tabular}{lcc}
\hline & $\begin{array}{c}\text { Control } \\
(n=13)\end{array}$ & $\begin{array}{c}\text { Acidotic } \\
(n=12)\end{array}$ \\
\hline $\mathrm{O}_{2}$ consumption without $\mathrm{ADP}, \mu M / \mathrm{mg} / \mathrm{min}$ & $32 \pm 3.6$ & $31 \pm 3.3$ \\
$\mathrm{O}_{2}$ consumption with $\mathrm{ADP}, \mu M / \mathrm{mg} / \mathrm{min}$ & $94 \pm 8.9$ & $84 \pm 8.5$ \\
$\mathrm{ADP}: \mathrm{O}$ & $2.6 \pm 0.17$ & $2.5 \pm 0.15$ \\
\hline
\end{tabular}

through the permeable outer membrane (Table III). Similar results were obtained with both the silicone layer and Millipore methods. Thus we could not demonstrate under any of the conditions tested that glutamine as such enters the matrix space. $\left[{ }^{14} \mathrm{C}\right]$ glutamate accounted for most of the remaining ${ }^{14} \mathrm{C}$ in the mitochondrial pellet (unidentified ${ }^{14} \mathrm{C}$ was $7 \% \pm 1.7, n=14$ ). At $4^{\circ} \mathrm{C}$, about one third as much glutamate was present in the matrix space as at room temperature, and with a 10 -fold increase in medium glutamine concentration, there was only a threefold increase in $\left[{ }^{14} \mathrm{C}\right]$ glutamate concentration in the mitochondria (Table III).

In further attempts to demonstrate glutamine within the matrix space by inhibiting glutamine deamidation, we used several compounds reported to be inhibitors of extracted glutaminase. However, the effect of these substances on glutamine deamidation by intact mitochondria did not always correspond to that predicted from the effect on the solubilized enzyme (Table IV). Thus borate, reported to inhibit glutaminase (20), stimulated matrix ${ }^{14} \mathrm{C}$ uptake and mitochondrial ammonia production. 6-diazo-5-oxo-L norleucine (DON) and azaserine, analogs of glutamine that strongly inhibit glutamine metabolism under some circumstances (21), had little effect in intact kidney mitochondria on glutamine uptake or deamidation, even when present in concentrations ten times greater than that of glutamine. On the other hand, p-chloromercuribenzoate (PCMB), a competitive inhibitor of glutaminase I (22), along with mersalyl (another organomercurial) completely inhibited matrix ${ }^{14} \mathrm{C}$ uptake and glutamine deamidation at concentration of $5 \times 10^{-4} \mathrm{M}$. Despite the absence of glutamine deamidation in the presence of PCMB or mersalyl, no glutamine was present in the matrix space (Table IV).

The absence of any glutamine within the matrix space is unexpected and is of considerable significance in interpreting these results, so that the magnitude of the errors inyolyed in these measurements needs to be con- 
TABLE III

$\left[{ }^{14}\right]$ CGlutamine and $\left[{ }^{11} \mathrm{C}\right]$ Glutamate Content of Mitochondria after Incubation in Media Containing $\left[{ }^{14} \mathrm{C}\right]$ Glutamine for $1 \mathrm{Min}$

\begin{tabular}{|c|c|c|c|c|c|}
\hline \multirow[b]{2}{*}{ Technique* } & \multirow{2}{*}{$\begin{array}{l}\text { Medium glutamine } \\
\text { concentration, } \\
\text { incubation temp. }\end{array}$} & \multicolumn{2}{|c|}{$\left[{ }^{14} \mathrm{C}\right]$ glutamine } & \multicolumn{2}{|c|}{$\left[{ }^{14} \mathrm{C}\right]$ glutamate in matrix space } \\
\hline & & Control & Chronic acidosis & Control & Chronic acidosi \\
\hline & & \multicolumn{2}{|c|}{$\%$ of that expected in outer space } & \multicolumn{2}{|c|}{$m M$} \\
\hline Silicone & $\begin{array}{l}1 \mathrm{mM} \text {, room temp. } \\
10 \mathrm{mM} \text {, room temp. } \\
1 \mathrm{mM}, 4^{\circ} \mathrm{C}\end{array}$ & $\begin{array}{c}92 \pm 1.17 \\
n=12 \\
97 \pm 4.0 \\
n=7 \\
94 \pm 3.7 \\
n=6\end{array}$ & $\begin{array}{c}87 \pm 4.0 \\
n=8 \\
100 \pm 4.2 \\
n=8 \\
-\end{array}$ & $\begin{array}{c}1.7 \pm 0.14 \\
n=12 \\
5.1 \pm 0.1 \\
n=7 \\
0.6 \pm 0.13 \\
n=6\end{array}$ & $\begin{array}{c}7.5 \pm 0.6 \\
n=8 \\
11.6 \pm 1.1 \\
n=7 \\
-\end{array}$ \\
\hline Pellet & $10 \mathrm{mM}, 4^{\circ} \mathrm{C}$ & $95,91,88 \ddagger$ & $67,65,84 \ddagger$ & $0.8,0.7,1.1 \ddagger$ & $2.7,3.3,2.0 \ddagger$ \\
\hline Millipore & $\begin{array}{l}1 \mathrm{mM} \text {, room temp. } \\
10 \mathrm{mM} \text {, room temp. } \\
1 \mathrm{mM}, 4^{\circ} \mathrm{C}\end{array}$ & $\begin{array}{c}95 \pm 1.1 \\
n=10 \\
105,103,97 \ddagger \\
93,90,96 \ddagger\end{array}$ & $\begin{array}{c}88 \pm 2.9 \\
n=7 \\
102,104,92 \ddagger \\
91,95,96 \ddagger\end{array}$ & $\begin{array}{c}1.3 \pm 0.26 \\
n=6 \\
- \\
-\end{array}$ & $\begin{array}{c}6.0 \pm 1.13 \\
n=6 \\
- \\
-\end{array}$ \\
\hline
\end{tabular}

* See Methods for details.

$\ddagger$ Results of individual experiments.

sidered. Underestimation of the glutamine space might arise in two ways; if glutamine radioactivity were lost from the mitochondria during the separation of mitochondria from medium, i.e. while the mitochondria were passing through the silicone oil layer, or if glutamine radioactivity were lost during the subsequent analytical procedures. Errors arising from the latter can be readily estimated from the recovery of known amounts of $\left[{ }^{14} \mathrm{C}\right]$ glutamine added to perchloric acid and then treated identically to the samples. Results of such experiments showed recovery of $97 \% \pm 1.6(n=10)$ of added radioactive glu- tamine. (If contamination of the glutamine fraction with other labeled metabolites occurred, it would result in overestimation of the glutamine space.) Errors arising from the first source, that is, from loss of glutamine radioactivity before entry into the acid layer, could occur if outer space fluid was left behind in the silicone oil. However, such losses would cause proportionate decreases in both $\left[{ }^{14} \mathrm{C}\right]$ glutamine and $\left[{ }^{3} \mathrm{H}\right]$ mannitol and would be compensated for in calculating the outer space volume. A more significant possible error during the separation stage is a disproportionate loss of $\left[{ }^{14} \mathrm{C}\right]$ glutamine aris-

TABLE IV

Effect of Inhibitors of Glutaminase on Mitochondrial $\left[{ }^{14} \mathrm{C}\right]$ Glutamine Uptake and Mitochondrial $\mathrm{NH}_{3}$ Production

\begin{tabular}{|c|c|c|c|}
\hline Inhibitor & Matrix ${ }^{14} \mathrm{C}$ uptake* & $\begin{array}{c}\left.{ }^{[14} \mathrm{C}\right] \text { Glutamine } \\
\text { distribution* }\end{array}$ & $\begin{array}{l}\text { Intact mitochondrial } \\
\mathrm{NH}_{3} \text { production* }\end{array}$ \\
\hline & $\%$ of controls & $\%$ of outer space & $\%$ of controls \\
\hline Borate, $1 \mathrm{mM}$ & $149 \pm 7.7(n=6)$ & $80,90 \%(n=2)$ & $145 \pm 10(n=6)$ \\
\hline \multicolumn{4}{|l|}{ PCMB } \\
\hline $0.05 \mathrm{mM}$ & $79.6 \pm 10.0(n=5)$ & $100,100 \%(n=2)$ & - \\
\hline $0.5 \mathrm{mM}$ & $0 \% \pm 0(n=6)$ & $100 \%(n=6) \ddagger$ & $11.2 \pm 1.0(n=4)$ \\
\hline \multicolumn{4}{|l|}{ Mersalyl } \\
\hline $0.05 \mathrm{mM}$ & $70.4 \pm 14.2(n=5)$ & $100,100 \%(n=2)$ & $一$ \\
\hline $0.5 \mathrm{mM}$ & $0 \% \pm 0(n=6)$ & $100 \%(n=6) \ddagger$ & $5,7 \%(n=2)$ \\
\hline DON, $10 \mathrm{mM}$ & $86,94(n=2)$ & $98,100(n=2)$ & $60,76(n=2)$ \\
\hline Azaserine, $10 \mathrm{mM}$ & $84,90(n=2)$ & $100,100(n=2)$ & $90,100(n=2)$ \\
\hline
\end{tabular}

* The matrix ${ }^{14} \mathrm{C}$ uptake and the intact mitochondrial $\mathrm{NH}_{3}$ production are expressed as the percent of the values obtained simultaneously in uninhibited control mitochondria. The $\left[{ }^{14} \mathrm{C}\right]$ glutamine distribution represents the percent of the outer (mannitol) space filled by labeled glutamine.

$\ddagger$ Matrix ${ }^{14} \mathrm{C}$ uptake was 0 , therefore there was no $\left[{ }^{14} \mathrm{C}\right]$ glutamine within the matrix space. 


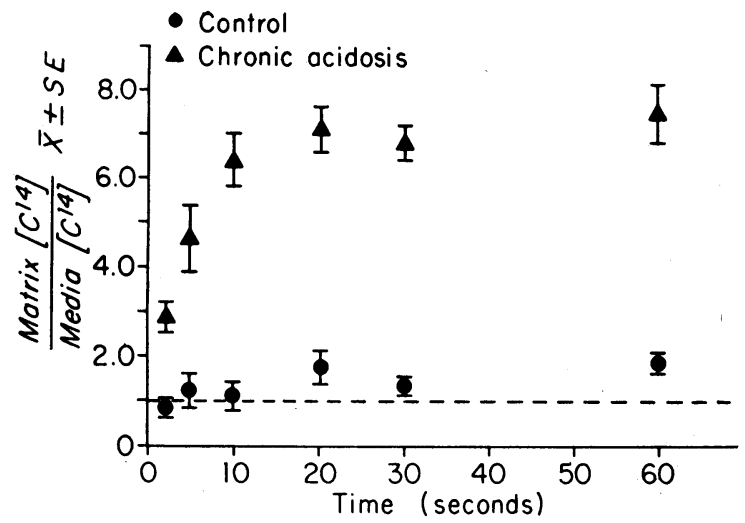

FIGURE 1 Time-dependent uptake of $\left[{ }^{11} \mathrm{C}\right]$ glutamine into the matrix space of kidney mitochondria from control and chronic acidotic rats when incubated in a medium containing $1 \mathrm{mM}\left[{ }^{14} \mathrm{C}\right]$ glutamine, $\mathrm{pH} \mathrm{7.4}$, at room temperature.

ing from metabolism of glutamine during transit through the silicone oil layer. This problem was encountered in mitochondria incubated at room temperature in 1 $\mathrm{mM}$ glutamine, in which the glutamine space was less than the outer space volume, especially in acidotic mitochondria (Table III). Three methods were used to diminish glutamine utilization during separation: low temperature, presence of PCMB or mersalyl, and use of the more rapid Millipore separation method. In none of these did the amount of glutamine exceed that present in the outer space, even though glutamate formation virtually ceased at low temperature and in the presence of inhibitors. These results do not exclude the possibility of the presence of glutamine in the matrix space at a concentration of less than $0.1 \mathrm{mM}$ when a medium concentration of $1 \mathrm{mM}$ was used.

$\left[{ }^{14} \mathrm{C}\right]$ Glutamine metabolism in chronic acidosis. Fig. 1 shows the time-dependent uptake of ${ }^{14} \mathrm{C}$ (to $60 \mathrm{~s}$ ) into the matrix space of renal mitochondria obtained from control and acidotic rats and incubated with $1 \mathrm{mM}$ $\mathrm{L}-\left[{ }^{14} \mathrm{C}\right]$ glutamine. We observed a fourfold increase in steady-state concentration in the acidotic group (matrix ${ }^{14} \mathrm{C}$ uptake: control $1.93 \pm 0.17, n=28$; acidotic 7.7 $\pm 0.65, n=23 ; P<0.0005)$. In these samples from acidotic rats, as in control rats, there was no detectable glutamine within the matrix space and most of the remaining counts represented $\left[{ }^{14} \mathrm{C}\right]$ glutamate accumulation in the matrix space (Table III) (unidentified ${ }^{14} \mathrm{C}$ was $13 \% \pm 2.8, n=10$ ). Compared to control mitochondria, $\left[{ }^{14} \mathrm{C}\right]$ glutamate in the matrix space was four times greater in acidotic mitochondria, and this was true with different methods of incubation and separation (Table III). The endogenous pool of glutamate, measured by an enzymatic fluorometric method (23), was always less than $0.5 \mathrm{mM} /$ liter of matrix space in mitochondria obtained from either control or acidotic rats. The $\left[{ }^{14} \mathrm{C}\right]$ glutamate content of the medium was also measured at room temperature, with $1 \mathrm{mM}\left[{ }^{14} \mathrm{C}\right]$ glutamine as substrate. In six control experiments, the medium glutamate was $0.008 \pm 0.002 \mathrm{mM}$ and in chronic acidosis, it was $0.016 \pm 0.003 \mathrm{mM}$, or less than $0.5 \%$ of the concentration found in the matrix space of these mitochondria. Because the concentration of glutamate in the medium was so low compared to that in the matrix space, we did not correct the matrix glutamate concentration for the negligible quantity of $\left[{ }^{14} \mathrm{C}\right]$ glutamate present in the outer space.

Chronic acidosis induced a sixfold increase in extracted glutaminase levels (specific activity at $37^{\circ} \mathrm{C}$, control $0.2 \pm 0.01 \mathrm{U} / \mathrm{mg}, n=25$; acidotic $1.2 \pm 0.18, n$ =13).

Glutamine metabolism after $3 h$ of acidosis. There was no increase in PDG levels extracted from the renal mitochondria of rats killed $3 \mathrm{~h}$ after the induction of acidosis compared to controls (specific activity at $37^{\circ} \mathrm{C}$, control $0.198 \pm 0.01 \mathrm{U} / \mathrm{mg}$, acidotic $0.200 \pm 0.039, P>$ 0.4 or paired $t P>0.3$ ) (Fig. 2), a finding in agreement with that of other investigators $(24,25)$. However, these mitochondria showed a significant increase in matrix ${ }^{14} \mathrm{C}$ uptake (Fig. 2) from $1.9 \pm 0.14$ in the controls to $2.6 \pm 0.2$ in the acidotic group. This difference is significant at the $P<0.01$ level, when the data are analyzed on a group basis, or at the $P<0.0005$ level, when analyzed as paired data. The average percent difference between the matrix ${ }^{14} \mathrm{C}$ uptake in the control and 3-h acidotic preparations was $39 \pm 3.8 \%$; while this difference is much less than the $400 \%$ increase seen with chronic acidosis, it was consistently present and was found in every one of 25 experiments. In six experiments, mitochondrial $\left[{ }^{14} \mathrm{C}\right]$ glutamate was determined in control and 3-h acidotic animals by the Millipore separation method. In the controls, the concentration of glutamate in the matrix space was 1.3

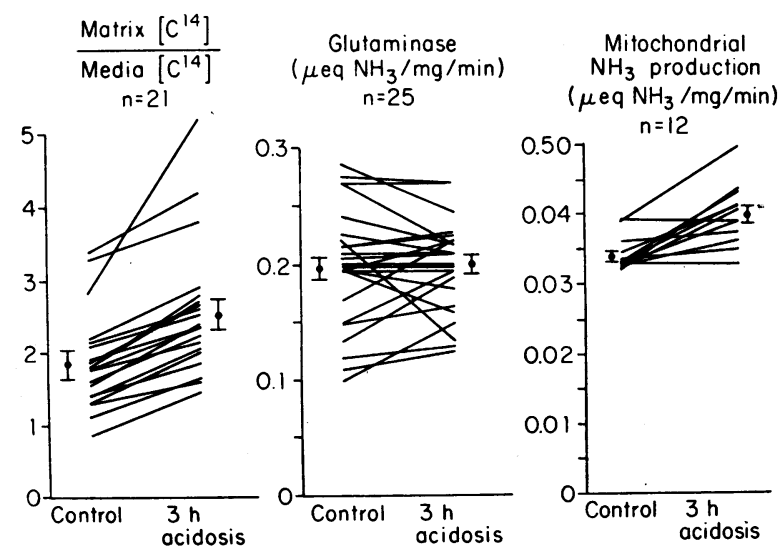

FIGURE 2 a. ${ }^{14} \mathrm{C}$ uptake from $\left[{ }^{14} \mathrm{C}\right]$ glutamine, $b$. extracted glutaminase levels, and $c$. ammonia production by intact mitochondria from kidneys of control and 3-h acidotic rats. ${ }^{14} \mathrm{C}$ uptake was measured at $1 \mathrm{~min}$ and as described in Fig. 1. 


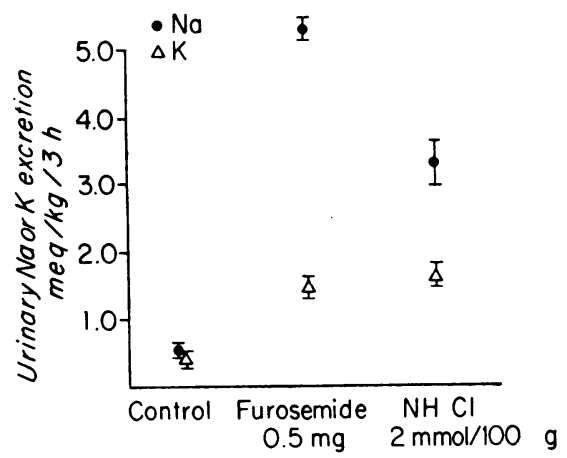

FIGURE 3 3-h urinary sodium and potassium excretion by conscious rats after an overnight fast and then either 5 $\mathrm{ml}$ water (control) I. G., furosemide, $0.5 \mathrm{mg}$ I.P. or 2 $\mathrm{ml} / 100 \mathrm{~g}$ of $1.0 \mathrm{~N} \mathrm{NH}_{4} \mathrm{Cl}$ intragastricly.

$\pm 0.26 \mathrm{mM}$ compared with $2.5 \pm 0.11 \mathrm{mM}$ in the shortterm acidotic group; the difference between groups is significant at the $P<0.01$ level. The mitochondria from the 3-h acidotic rats had a lesser, but still highly significant, increase in mitochondrial ammonia production (control $34 \pm 0.7 \mathrm{nM} \mathrm{NH} / \mathrm{mg}$ per min, acidotic $40 \pm 1.3, P<0.01$ or on a paired basis an increased uptake of $17 \% \pm 3.7$, paired $t$ test $P<0.0005$ ) (Fig. 2).

Comparison of acute $\mathrm{NH}_{4} \mathrm{Cl}$ loading with acute $\mathrm{Na}$ and $K$ depletion by furosemide. The 3-h urinary excretion of $\mathrm{Na}$ and $\mathrm{K}$ after an overnight fast followed by a water, $\mathrm{NH}_{4} \mathrm{Cl}$, or furosemide load is illustrated in Fig. 3. Furosemide produced a greater natriuresis and similar kaliuresis to $\mathrm{NH}_{4} \mathrm{Cl}$ loading. However, unlike $\mathrm{NH}_{4} \mathrm{Cl}$, furosemide caused no change in ${ }^{14} \mathrm{C}$ uptake

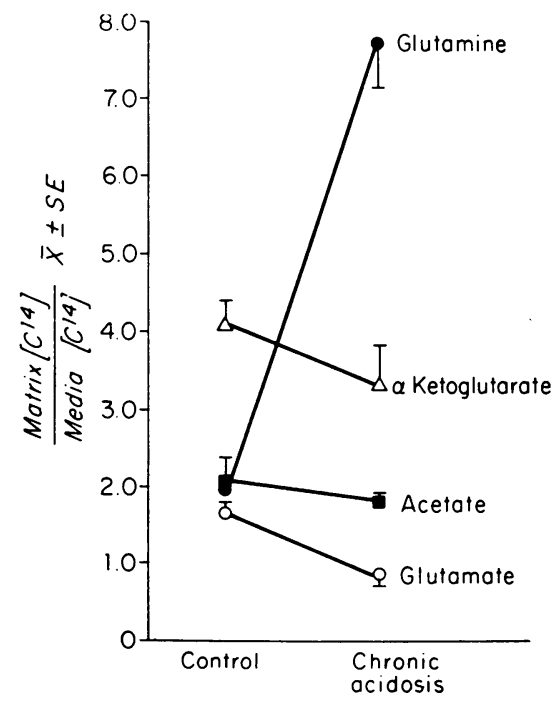

FIgURE 4 The matrix ${ }^{14} \mathrm{C}$ uptake in mitochondria from control and chronically acidotic rats when incubated in the same medium used in Fig. 1, except that instead of glutamine, it contained either $1 \mathrm{mM}\left[{ }^{14} \mathrm{C}\right]$ glutamate, $\alpha$-ketoglutarate, or acetate. in kidney mitochondria incubated in $1 \mathrm{mM}\left[{ }^{14} \mathrm{C}\right]$ glutamine (furosemide group ${ }^{14} \mathrm{C}$ uptake/control group ${ }^{14} \mathrm{C}$ uptake $=1.04 \pm 0.04, n=8$, paired $t, P>0.2$ ).

Specificity of adaptation in substrate uptake in chronic acidosis. Mitochondria from control or chronic acidotic rats were incubated for $60 \mathrm{~s}$ in media containing either $1 \mathrm{mM}\left[{ }^{14} \mathrm{C}\right]$ glutamine, glutamate, $\alpha$-ketoglutarate, or acetate. Only with glutamine was there an increased steady-state level of ${ }^{14} \mathrm{C}$. With acetate, there was no difference in uptake of ${ }^{14} \mathrm{C}$ (paired $t, P>0.3$ ), and with glutamate and $\alpha$-ketoglutarate there was a decreased ${ }^{14} \mathrm{C}$ level in the chronic acidotic group (degree of decreased ${ }^{14} \mathrm{C}$ uptake in acidotic group, glutamate $47 \% \pm 8.6$, paired $t$ test, $P<0.0005 ; \alpha$-ketoglutarate $15 \% \pm 6.1$, paired $t$ test, $P<0.05$ ) (Fig. 4).

\section{DISCUSSION}

These results confirm previous reports describing the rapid metabolism of glutamine by mitochondria from kidney and they show that $\left[{ }^{14} \mathrm{C}\right]$ glutamate formed from labeled glutamine is concentrated in the matrix space (26-28). For such glutamate formation to occur, glutamine must penetrate the inner mitochondrial membrane and reach the site of glutaminase. We may then ask what the nature of the mechanism enabling glutamine to penetrate the inner membrane is. Is it a passive or carrier-mediated process? If a carrier is involved, what role does it play in regulating the rate of glutamine metabolism?

A surprising finding in this series of experiments is the observation that $\left[{ }^{14} \mathrm{C}\right]$ glutamine, as such, is not detectable in the matrix space even though the method is sensitive enough to detect a glutamine concentration less than $10 \%$ of that present in the medium. In contrast, most other substrates for matrix space enzymes such as citrate, malate, or $\alpha$-ketoglutarate are concentrated in the matrix space to levels considerably in excess of those present in the medium (10). Lack of demonstrable glutamine in the matrix space might result from a combination of relatively slow passive diffusion of glutamine across the inner membrane, followed by

\footnotetext{
4 Our results concerning the distribution of glutamine in rat kidney mitochondria are at variance with recent results reported for pig kidney mitochondria by Crompton and Chappell, who found labeled glutamine in the matrix space after incubation of mitochondria containing $\left[{ }^{14} \mathrm{C}\right]$ glutamine and $\left[{ }^{14} \mathrm{C}\right]$ glutamate $(28)$. However, using medium identical to that described by these authors, we could not demonstrate glutamine in the matrix space of rat kidney mitochondria either at room temperature or at $4^{\circ} \mathrm{C}$ (unpublished observation). This difference may represent a species difference or may be the result of differences in technique. These authors also suggest the existence of a coupled glutamine/glutamate exchange in kidney mitochondria. Our results, while compatible with this postulated mechanism, provide evidence neither for nor against it.
} 
rapid conversion to glutamate by glutaminase. If this were the case, then inhibition of glutamate formation would allow passive entry of glutamine into the matrix until it reached an equilibrium concentration readily measured by our methods. Since we failed to detect glutamine in the matrix when glutamate formation was inhibited by low temperature or mersalyl or PCMB, none of which would have an appreciable effect on passive diffusion, this mode of transport is eliminated as a means by which glutamine crosses the inner membrane. Consequently, we must postulate that a carrier mechanism is involved in the translocation of glutamine at this site.

There are two distinct types of carrier processes that might be involved in the transport of glutamine: the inner membrane carrier might transport and release glutamine molecules into the matrix space, where they are then available to glutaminase for deamidation, or a close coupling might exist between the carrier and glutaminase so that, in the course of transit across the inner membrane, glutamine is deamidated, resulting in the release of glutamate but not glutamine into the matrix space. The results of the present experiments do not permit us to choose between these two possibilities and either could be correct. Whichever is correct, we can draw certain similar conclusions about the role of transport in regulating glutamine metabolism.

In the first of the above possibilities, in which glutamine is transported across the inner membrane and released as such into the matrix space before being deamidated, the transport process resembles in form those described for other mitochondrial substrates (10). In this case, since we are unable to detect glutamine in the matrix space, despite widely differing rates of glutamate formation under different experimental conditions, it must be that all the available glutamine is deamidated by glutaminase immediately upon entering the matrix space and hence the transport process is the rate-limiting step in glutamine deamidation. The clearest evidence of this conclusion comes from the experiments in which the concentration of glutamine in the medium was increased from 1 to $10 \mathrm{mM}$; the rate of glutamate formation rose only threefold with this tenfold increase in substrate concentration, but no glutamine was detectable in the matrix space. If the activity of glutaminase was rate-limiting in this situation, then glutamine should have been found in the matrix space. Since it was not, transport rather than deamidation must have been the slower process. Activity of the glutaminase reaction in the presence of a very low matrix space glutamine level (that is, one which we could not detect) cannot be excluded. The activity of this enzyme, undamaged and unaltered by separation from mitochondria, is unknown, as is its affinity for glutamine (published $K_{m}$ values do not necessarily reflect those of the enzyme in intact mitochondria) and in addition the reaction proceeds virtually irreversibly to glutamate formation (20).

Thus, regardless of whether glutamine is released as such into the matrix space or whether it is deamidated in the inner membrane, our results indicate that the rate of movement of glutamine across the membrane is the rate-limiting step in ammoniagenesis. Consequently, any process that stimulates glutamine utilization by mitochondria must stimulate the uptake of glutamine by its inner membrane carrier.

Physiologically, the most important situation in which ammonia production from glutamine is increased is chronic metabolic acidosis. The primary mechanism responsible for this change is so far unexplained. Although renal glutaminase levels are increased in the rat $(29,30)$, this alteration only occurs some hours after increased ammonia production develops $(24,25)$. In addition, simultaneous administration of actinomycin $\mathrm{D}$ with an acid load prevents the development of increased glutaminase levels but not the increased ammonia production in the rat (31). In the dog, there is no increase in glutaminase levels, despite large increases in ammonia production in acidosis $(32,33)$. Thus there is considerable evidence that a rise in glutaminase in acidosis is not a primary or essential cause of the increased ammonia production from glutamine. Since the renal glutamate levels are decreased in acidosis in the rat $(34,35)$ and since glutamate is an end product inhibitor of glutaminase (34), others have postulated that removal of glutamate by, for example, increased gluconeogenesis would decrease end-product inhibition of glutaminase and stimulate ammonia production $(34,36)$. However evidence against this hypothesis has been presented (37-39) and the results of the present study, in which a higher glutamate content was present in the acidotic mitochondria, show clearly that the stimulus to glutamine utilization precedes glutamate formation. (The fact that tissue glutamate levels are decreased in acidosis but that our results show increased intramitochondrial glutamate concentration in acidosis need not represent a contradiction. In general, extrapolation of tissue levels to those existing within mitochondria is not warranted; a decrease in level of a metabolite in the cytoplasm could mask a much greater increase in concentration in the mitochondrial matrix space because of the large volume difference between cytoplasm and matrix.)

The results obtained in the experiments reported here need to be considered in relation to the two possibilities discussed earlier in this section, that the carrier and glutaminase are a single entity or that a glutamine carrier distinct from glutaminase exists in the inner membrane. If glutaminase both transports and metabo- 
lizes glutamine, the increased ${ }^{14} \mathrm{C}$ levels that we find in the matrix space of mitochondria from acidotic animals might result solely from the accompanying increase in activity in acidosis. However after only $3 \mathrm{~h}$ of acidosis, before any increase in the level of extracted glutaminase, there is a significant increase in the uptake of ${ }^{14} \mathrm{C}$ from $\left[{ }^{14} \mathrm{C}\right]$ glutamine and in ammonia production. While this finding does not exclude the possibility that glutaminase, in intact mitochondria, is activated early in acidosis by a mechanism not evident on assay of the extracted enzyme, it does show that increased transport of glutamine occurs in acidosis before demonstrable change in glutaminase activity. If the carrier and enzyme are separate entities, in which the carrier is rate-limiting, it is clear that the increase in glutaminase levels in chronic acidosis can result in increased ammonia production only if there is a concomitant increase in glutamine delivery to the enzyme. The evidence from the short-duration acidosis experiments suggests that such an adaptation of the glutamine carrier precedes that of the enzyme.

The adaptation in substrate transport is specific for glutamine, since it was not observed with glutamate, $\alpha$ ketoglutarate, or acetate. The slight decrease in the matrix concentrations of the two substrates actively transported across the inner membrane ( $\alpha$-ketoglutarate and glutamate) in the acidotic group is so far unexplained.

Potassium depletion, like acidosis, is known to stimulate renal ammonia production and to increase glutaminase levels in the rat $(40,41)$; the possibility exists that it is not the acidosis but concurrent potassium depletion, or even volume depletion, which produces the changes observed in these studies. However, in the 3-h acidotic rats, the potassium loss was negligible (less than $3 \%$ of total body potassium) and a similar degree of potassium loss and a greater degree of volume depletion produced by furosemide induced no change in $\left[{ }^{14} \mathrm{C}\right]$ glutamine transport. Thus metabolic acidosis per se appears to be responsible for stimulating the changes in mitochondrial glutamine metabolism.

In conclusion, there are two possible explanations for our results: First, glutamine is transported across the inner mitochondrial membrane by a specific carrier system with deamidation by glutaminase while crossing the membrane or immediately upon entering the matrix space. In this situation, the rate of transport is the controlling factor in glutamine utilization and in acidosis there is an adaptive increase in glutamine transport. The increased delivery of substrate to glutaminase enzyme then results in increased ammonia production. Second, glutamine is transported across the inner mitochondrial membrane by glutaminase, which also deamidates the glutamine. In the early stages of acidosis there is an increased activation of this reaction by some process not observed on assay of the extracted enzyme; in chronic acidosis, the increased levels of glutaminase provide both increased transport and deamidation.

Whichever of the above applies, our general conclusion is that transport of glutamine across the mitochondrial inner membrane occurs by a specific carrier, which may or may not be glutaminase. This step is the ratecontrolling factor in glutamine metabolism. In acidosis, an adaptation specific for the glutamine carrier is responsible for increased deamidation of this amino acid.

\section{ACKNOWLEDGMENTS}

We would like to thank Susan Brown, Wanda Lakner, and Gloria Roton for technical assistance.

This work was supported by NIH Grants AM-09822 and $\mathrm{AM}-06741$.

\section{REFERENCES}

1. Orloff, J., and M. Burg. 1971. Physiology of the kidney and body fluids. Anmu. Rev. Physiol. 33: 110-121.

2. Pitts, R. F. 1968. Physiology of the Kidney and Body Fluids. Year Book Medical Publishers, Inc., Chicago, I11. 2nd edition. 195-211.

3. Blackburn, E. J., and F. J. R. Hird. 1972. Metabolism of glutamine and glutamate by rat liver mitochondria. Arch. Biochem. Biophys. 152 : 258-264.

4. Crompton, M., J. D. McGivan, and J. B. Chappell. 1973. The intramitochondrial location of glutaminase enzymes. Biochem. J. 132: 27-34.

5. Katanuma, N., I. Tomino, and H. Nishino. 1966. Glutaminase isoenzymes in rat kidney. Biochem. Biophys. Res. Commun. 22: 321-328.

6. Curthoys, N. B., and O. H. Lowry. 1973. The distribution of glutaminase isoenzymes in the various structures of the nephron in the normal, acidotic and alkalotic rat kidney. J. Biol. Chem. 248: 162-168.

7. Kamm, D. E., and R. R. Asher. 1970. Relation between glucose and ammonia production in renal cortical slices. Am. J. Physiol. 218: 1161-1165.

8. Goldstein, L. 1967. Pathways of glutamine deamidation and their control in rat kidney. Am. J. Physiol. 213: 983-989.

9. Lehninger, A. L. 1964. The Mitochondrion. W. A. Benjamin, Inc., Menlo Park, Calif. 1st edition. 41-65.

10. Klingenberg, M. 1970. Metabolite transport in mitochondria: an example for intracellular membrane function. Essays Biochem. 6: 119-159.

11. Adam, W. R, and J. K. Dawborn. 1972. Potassium tolerance in rats. Aust. N. Z. J. Exp. Biol. Med. Sci. 50: 757-768.

12. Chappell, J. B., and R. L. Hansford. 1972. Preparation of mitochondria from animal tissues and yeasts. In Subcellular Components. Preparation and Fractionation. G. D. Birne, editor. University Park Press, Baltimore, Md. 2nd edition. 77-91.

13. Harris, E. J., and K. Van Dam. 1968. Changes in total water and sucrose space accompanying induced ion uptake or phosphate swelling of rat liver mitochondria. Biochem. J. 106 : 759-766.

14. Kraaijenhoff, R., C. S. Tsou, and K. Van Dam. 1969. The determination of the rate of uptake of substrates of rat-liver mitochondria. Biochim. Biophys. Acta. 172: $580-582$. 
15. Busch, A., R. B. Hurlburt, and V. R. Potter. 1952. Anion exchange chromatography of acids of the citric acid cycle. J. Biol. Chem. 196: 717-727.

16. Sherrard, D. J., and D. P. Simpson. 1969. An improved method for the microdetermination of glutamine in plasma and urine. J. Lab. Clin. Med. 73: 877-882.

17. Scribner, B. H., and J. C. Caillouette. 1954. Improved method for the bedside determination of bicarbonate in serum. J. Am. Med. Assoc. 155: 644-648.

18. Layne, E. 1957. Spectrophotometric and turbidimetric methods for measuring protein. Methods Enzymol. 3: 447-454.

19. Lowry, O. M., N. J. Rosebrough, A. L. Farr, and R. J. Randall. 1951. Protein measurement with the Folin phenol reagent. J. Biol. Chem. 193: 265-275.

20. Roberts, E. 1960. Glutaminase. Enzymes. 4: 285-300.

21. Hartman, S. C. 1970. Glutaminase and $\gamma$-glutamyl transferases. Enzymes. $4:$ 79-100.

22. Sayre, F. W., and E. Roberts. 1958. Preparation and some properties of a phosphate-activated glutaminase from kidneys. J. Biol. Chem. 233: 1128-1134.

23. Williamson, J. R., and B. E. Corkey. Assays of intermediates of the citric acid cycle and related compounds by fluorometric enzyme methods. Methods Enzymol. 13: 434-513.

24. Leonard, E., and J. Orloff. 1955. Regulation of ammonia excretion in the rat. Am. J. Physiol. 182: 131-138.

25. Alleyne, G. A. O., and G. H. Scullard. 1969. Renal metabolic response to acid-base changes. I. Enzymatic control of ammoniagenesis in the rat. J. Clin. Invest. 48: $364-370$

26. Hird, F. J. R., and M. A. Marginson. 1968. The formation of ammonia from glutamine and glutamate by mitochondria from rat liver and kidney. Arch. Biochem. Biophys. 127 : 718-724.

27. Kovacevic, Z., J. D. McGivan, and J. B. Chappell. 1970. Conditions for activity of glutaminase in kidney mitochondria. Biochem. J. 118: 265 .

28. Crompton, M., and J. B. Chappell. 1973. Transport of glutamine and glutamate in kidney mitochondria in relation to glutamine deamidation. Biochem. J. 132: 35-46.

29. Davies, B. M. A., and J. Yudkin. 1952. Studies in biochemical adaptation. The origin of urinary ammonia as indicated by the effect of chronic acidosis and alkalosis on some renal enzymes in the rat. Biochem. J. 52: $407-412$.
30. Rector, F. C., Jr., D. W. Seldin, and J. H. Copenhaver. 1955. The mechanism of ammonia excretion during ammonium chloride acidosis. J. Clin. Invest. 34: 20-26.

31. Goldstein, L. 1965. Actinomycin D inhibition of the adaptation of renal glutamine-deaminating enzymes in the rat. Nature (Lond.). 205: 1330-1331.

32. Rector, F. C., Jr., and J. Orloff. 1959. The effect of administration of sodium bicarbonate and ammonium chloride on the excretion and production of ammonia. The absence of alterations in activity of renal ammoniaproducing enzymes in the dog. J. Clin. Invest. 38: 366372.

33. Pollak, V. E., H. Mattenheimer, H. DeBruin, and K. J. Weinman. 1965. Experimental metabolic acidosis: the enzymatic basis of ammonia production in the dog kidney. J. Clin. Invest. 44 : 169-181.

34. Goldstein, L., 1966. Relation of glutamate to ammonia production in the rat kidney. Am. J. Physiol. 210: 661666.

35. Damian, A. C., and R. F. Pitts. 1970. Rates of glutaminase $\mathrm{I}$ and glutamine synthetase in rat kidney in vivo. Am. J. Physiol. 218: 1249.

36. Goodman, A. D., R. E. Fuisz, and G. F. Cahill, Jr. 1966. Renal gluconeogenesis in acidosis, alkalosis and potassium deficiency. Its possible role in the regulation of renal ammonia production. J. Clin. Invest. 45: 612619.

37. Pitts, R. F., L. A. Pilkington, M. B. MacLeod, and E. Leal-Pinto. 1972. Metabolism of glutamine by the intact functioning kidney of the dog. Studies in metabolic acidosis and alkalosis. J. Clin. Invest. 51: 557-565.

38. Kamm, D. E., and G. L. Strope. 1972. The effects of acidosis and alkalosis on metabolism of glutamine and glutamate in renal cortex slices. J. Clin. Invest. 51: 1251-1263.

39. Simpson, D. P. 1972. Pathways of glutamine and organic acid metabolism in renal cortex in chronic metabolic acidosis. J. Clin. Invest. 51: 1969-1978.

40. Iacobellis, M., E. Muntwyler, and G. E. Griffen. 1952. Enzyme concentration changes in the kidneys of protein- and/or potassium-deficient rats. Am. J. Physiol. 178: 477-482.

41. Pagliara, A. S., and A. D. Goodman. 1970. Relation of renal cortical gluconeogenesis; glutamate content and production of ammonia. J. Clin. Invest. 49: 1967-1974. 